\title{
COMPARATIVE EDUCATION IN THE EDUCATIONAL SYSTEMS AND PROBLEMS IN LIKENESSES AND DIFFERENCES BETWEEN REGIONS OF THE WORLD
}

\author{
1Monica Steinbach and ${ }^{2}$ Shahrzad Afroozeh \\ ${ }^{1}$ Education University of Vienna, Austria \\ ${ }^{2}$ Department of Philosophy, University of Vienna, Vienna, Austria \\ Email: monica_steinbach@ymail.com
}

Received: Feb 20, 2016

Accepted: Apr 7, 2016

Published: Sep 28, 2016

Article Url: https://journal.scadindependent.org/index.php/jipeuradeun/article/view/107

\begin{abstract}
This paper is to consider the term "comparative" in its more restricted sense, in the way the term is used in various comparative fields of study. It is somewhat curious that scholars in our field of comparative education have never attempted to sort out the various meanings of the term "comparative." I do not plan to draw a firm distinction between the two spheres, though it might be helpful to suggest that "comparative education" is generally regarded as the more academic or scientific aspect of the field, while international education is related to "cooperation, understanding, and exchange" elements of the field. I feel we must reject the hegemonic claims of science. We recall, for example, that Comte believed society traversed through various stages, from religion, to philosophy, then to science. His mistake, from my vantage point, was to place these ways of knowing in a hierarchical framework, which makes philosophy a second-rate means of knowing, and religion a third-rate means of knowing. My own orientation is to place them parallel with each other. There is a place for the spiritual, a place for the philosophical, and a place for the scientific, and any attempt to place one exclusively over the other is inappropriate.
\end{abstract}

Keywords: Comparative, Education, Regions, Words, Problems in Likenesses 


\section{A. Introduction}

Comparative and International Education Society (CIES) was originally known as the Comparative Education Society and in 1972 during his tenure as president Stewart Fraser was successful in adding the term "International." We do not plan to draw a firm distinction between the two spheres, though it might be helpful to suggest that "comparative education" is generally regarded as the more academic or scientific aspect of the field, while international education is related to "cooperation, understanding, and exchange" elements of the field (Fraser and Brickman 1968). I shall address some issues related to CIES, for I feel all too little attention is given to the meanings of the labels "comparative" and "international" in our society.

We would like to concentrate on the term "comparative" as used in comparative education. In some respects the term comparative studies has been unfortunate, because most knowledge is comparative in nature. In terms of education, Thomas points out that comparative education is generally defined in practice in a more restricted sense. That is, it refers to the "study of educational likenesses and differences between regions of the world or between two or more nations" Stewart Fraser and William Brickman (1968: 1) would agree with Thomas in their own definition of the field: "Comparative Education is the analysis of educational systems and problems in two or more national environments in terms of socio-political, economic, cultural, ideological, and other contexts." Such definitions are similar to those in other social science comparative fields. Comparative Sociology, for example, has been defined as any specifically cross-cultural or cross-societal, comparison of similarities and differences between social phenomena (Jary and Jary 1991: 103). R. Murray Thomas (1998: 1) reminds us that "in its most inclusive sense, comparative education refers to inspecting two or more educational entities or events in order to discover how and why they are alike and different".

This paper is to consider the term "comparative" in its more restricted sense, in the way the term is used in various comparative fields of study. It is somewhat curious that scholars in our field of comparative education have never attempted to sort out the various meanings of the term "comparative". 
We likely accept uncritically the notion that many fields have their comparative subfield and make the assumption that all comparative fields have so much in common that it is not necessary for us to dwell on the specific meanings of the term.

\section{B. Origins of Comparative Studies}

Comparative studies emerged at a crucial time in the world's history. Europeans were discovering the rest of the world and attempting to explain its many variations. A belief in natural law required making assessments of how governments, family, and civil society were organized. These developments contributed to the rise of comparative studies. Science was particularly important in the development of comparative studies, and early comparative scholars uniformly identified their field as one which relied on the use of "scientific methodology" (Jordan: 1905).

Comparative studies initially emerged in the life sciences, as subfields of anatomy, paleontology, and embryology. These life sciences established the main form that comparative studies would take by emphasizing hierarchical classification. To classify is to arrange items or data into groups, and the classification scheme of comparative life sciences was based on the assumption of a hierarchy of life forms. ${ }^{1}$

Comparative anatomy, for example, assumed that animal life consisted of a so-called "scale of being," or a "ladder of creation" and animal groups occupied different rungs or steps on that ladder. The comparative anatomist compared organs and organ systems in order to determine the variations to be found in God's creation. With the emergence of the theory of evolution, comparative anatomy was revolutionized in that the various animal archetypes on this ladder of creation were seen as progressive steps in the evolutionary process. Life forms were thought to move along a number of evolutionary lines from the simple to the complex. In the nineteenth century all of these fields were based on a common assumption that there is a hierarchy of life forms, with human beings constituting the highest life form.

\footnotetext{
${ }^{1}$ The process of classification is always somewhat arbitrary, but a comparative classification scheme usually satisfies at least two criteria: communicability and comprehensiveness. In terms of communicability, the scheme must be of value to those who wish to communicate with each other, so the groupings and their relations must be understood and seen as useful to scholars. In terms of comprehensiveness, the scheme must be so designed that all elements of any system could logically be placed within some category.
} 


\section{Comparative Studies in the Social Sciences}

We recall, that Auguste Comte (1998: 132-37), the father of sociology, gave credit to physiology for much of his thinking, and his notion of society corresponds strikingly with the "ladder of being" in anatomical studies. According to Comte, the major work of sociologists would be to investigate societies and place them in their appropriate evolutionary stage of development. That is, he believed societies evolved through a series of set stages, with Europe at the pinnacle of this process. Social evolution consisted of three primary stages: the theological (religious), then the metaphysical (philosophical), and finally the positive (scientific) stage. In his theory he distinguished between "statics" and "dynamics." His statics would be echoed by those stressing the social order and functionalism, while his dynamics would be emphasized by those interested in changes taking place in society and the forces that would contribute to these changes.

In the second half of the nineteenth century, sociology developed into a recognized discipline, and its founders developed a paradigm that followed Compte's conceptual frame in that societies were seen to progress through several stages, including the primitive stage, the traditional stage and finally the modern stage. The final two stages represented a dichotomous social construct, the modern world forming one ideal extreme of the construct and the traditional forming the other. This framework echoes Herbert Spencer's homogeneity and differentiation, Max Weber's traditionalism and rationalism, Emile Durkheim's organic to mechanical organization, and Ferdinand Tönnies' community and society. This dichotomous framework suggests a linear movement between two extremes. A nation is believed to modernize when it looses its traditional characteristics and takes on modern characteristics. It is important to note that not all of the scholars mentioned above saw the modern as an advance over the traditional. Durkheim (1893), for example, saw the shift from an organic to a mechanical social life to be a step backward in social organization .

A basic assumption of the comparative sociologists has been that a hierarchy of social forms exists and the task of the comparativist is to 
classify the various societies and place them in their appropriate hierarchical station.

A substantial amount of research in comparative education has been based on a similar assumption that there is a developmental hierarchy of social and educational structures. This was the pervasive paradigm in the social sciences at the time comparative education became a legitimate subfield in education in the years following World War II. One reason the field of comparative education took off was the central role accorded to education in national development, foreign aid, and economic investment. And according to scholars such as Philip Altbach (1991), modernization theory remains today one of the defining features of comparative education, though in recent years it has been somewhat discredited. For example, Samuel Huntington (1971: 294) complained that the modern ideal is set forth, "then everything which is not modern is labeled traditional." The greatest challenges to modernization have come from the so-called conflict oriented social scientists. One of the more popular theories in this paradigm, for example, has been world systems theory, which is based on the notion that the world is controlled and ruled by capitalism, located in core nations, and ruled by those who profit from the capitalist system. The rest of the world is located in the so-called semiperiphery or periphery countries, which are seen to be largely exploited and victimized by the core nations. And even more recently, the notion of globalization has become a dominant theme in international work. Though it incorporates political and cultural globalism, it remains mainly centered on the notion of a global capitalist system that defines our lives (Wallerstein: 1991). We often forget that much of this recent work stems conceptually from Karl Marx, who also saw societies forming a clear hierarchy and historical movement through various stages. ${ }^{2}$ World systems and globalization theories are conceptual constructs based as

\footnotetext{
${ }^{2}$ This conceptual frame formed the core of history study in public schools of countries under the influence of the Soviet Union. In East Germany, for example, the history curriculum was six years in length and it was based on the notion that mankind has progressed through a series of epochs: original society, slave society, feudal society, early capitalism, imperialistic capitalism, and finally socialism. In each of the epochs, progressive forces were at work to move society to another level of development, while reactionary forces were attempting to prevent its Development.
} 
much on interpretation as on historical fact, but they play a powerful role in the thinking of comparative educators. Even though the hierarchical developmental paradigm outlined above continues to loom large in the field of comparative education, alternative notions are also found.

\section{Social Systems and Structures}

One of the main variations in classification work among comparativists is the attempt to classify social systems and structures that do not suggest evolutionary or hierarchical arrangements. Comparative politics is particularly known for its ahistorical attempts to develop categories representing the contemporary political world. Even though it has also given some attention to modernization and political development, its primary comparative politics legacy, is its interest in classifying the types of regimes that exist, finding language equivalents in different political systems, and classifying their respective functions. We are all familiar with the following ways of ruling: the rule of the one (monarchy), the rule of the few (aristocracy), and the rule of the many (democracy). There is no suggestion in the scheme that one form of rule evolved from another form, or that one is even better than another. In fact, each type has its shadow side in that a monarchy can degenerate into a tyranny or despotism, an aristocracy can become an oligarchy, and a democracy can become a mob or chaotic form of ruling.

Similarly, specialists in comparative law are interested in the normative content of various legal systems. They attempt to define families of legal systems such as Roman law, common law, or socialist law, and identify the norms and ways of thinking that take place within these legal families.

Whereas ahistorical typologies dominate certain comparative fields, comparative education has given little attention to national typologies. This appears to be so foundational that a comparative field is almost unable to exist in any meaningful sense unless the objects of study have been classified in some rigorous manner so that research is cumulative. Comparative educators have relied on typologies drawn from other fields, but have done little to extend and enhance the form of educational typologies. It is true that Marc Antoine Jullien, seen by many as the father of comparative education, 
was one of the first modern scholars to establish a classification design that would facilitate collecting and cataloguing data about different school systems. This scheme has been retained until this day (Holmes 1981: 89). The basic focus of most schemes was on levels and types of education, and it has long been apparent that the nomenclature and flexibility of the schemes were only approximately appropriate to most countries.

\section{Historical Approaches in Comparative Studies}

Comparative philology is a good case in point. Philologists generally feel it is inappropriate to suggest that languages evolved in the conventional sense of the term, because evolution generally implies the notion of progressive change or improvements, and comparative philologists have rarely been guilty of suggesting that one language form is superior to another. Rather, the philologist is content to trace the changes that occur in sounds, in words, in spelling, in grammar, etc., and joins the socio-linguist in studying the contextual forces connected with these language changes.

Franz Bopp, the founder of comparative philology, was mainly interested in the genesis of linguistic forms at least as they pertained to IndoEuropean languages (Delbrück: 1882). Those comparative philologists who followed Bopp believed the historical roots of language could only be reached through comparison (Sayce: 1892). They have attempted to piece together the history of the human species by engaging in a scientific study of the history of language. Contemporary comparative philology, now usually called comparative linguistics, has continued to focus on the reconstruction of earlier forms of language and the changes that have taken place in these languages.

The study of history played a significant role as the field of comparative education was being defined. Many early pioneers of the field were themselves historians, including Robert Ulich, Isaac Kandel, Harold Benjamin and William W. Brickman. Those who wrote the early textbooks, including Isaac Kandel (1933) as well as I. N. Thut and Don Adams (1964), took a historical approach to their country studies. However, their work deviated markedly from that of the comparative philologists. First, whereas philology has maintained a focus on language origins, little attention is given in comparative education to the origins of any aspect of education. Rather, 
history of education is usually outlined in order to provide a sense of context and the social setting in which a particular educational problem is situated. Second, there has generally been a methodological flaw in the historical accounts of comparative educators. Because early comparative education was global in nature, the historical studies these pioneers of the field produced were based almost exclusively based on secondary sources. In fact, Auguste Comte (1988) argued that it was appropriate to rely on secondary sources when studying the history of a society. However, that tradition has not led to great credibility in their historical works. While historical studies play some role in contemporary comparative education, it is not significant.

\section{Comparative literature and Influences across Cultures}

Some comparative fields focus mainly on influences within and across cultures. Comparative literature is a primary example of this type orientation in that these comparative scholars attempt to unravel interrelationships between individuals, schools of thought, or national literatures across time and space. In terms of space, the comparative literature scholar wishes to trace the movement of themes and genres from place to place, how religious themes in Switzerland migrated to the Netherlands, then to America; how Tolstoi, Emerson and Thoreau influenced Indian writers in South Asia; how Africa incorporates European writing styles; how the Don Juan archetype moves from culture to culture (e.g., Samuel and Shanmugham 1980; Weisstein 1968; Weisbuch 1989; Highet 1992).

Some important work has been done in comparative education related to tracing influences in educational change and reform. Frederick Schneider (1943) devoted most of his period of exile in Nazi Germany tracing the influences of German education on other countries.

We would conclude that though the tracing of influences can be found in comparative education studies they do not constitute any systematic research agenda of those in the field. Whereas comparative literature has developed a systematic framework to chart a cumulative literature on influences, comparative education work regarding influences remains sporadic and non-cumulative. 


\section{Discussion}

With this all too superficial review, it has been possible to characterize various comparative fields, that comparative anatomy has a hierarchical comparative classification; comparative politics has a somewhat different orientation related to ahistorical typologies, while comparative philology traces the comparative development of languages, and comparative literature traces cultural influences across cultures. The question remains, are we able to characterize our own field of comparative education in some specific way. Certainly, developmental and ahistorical system typologies, and cultural influences have played some role in our field; however, we are inclined to characterize our work as relying mainly on hierarchical developmental classification.

In certain respects the many comparative approaches we see in our field is unfortunate, because we are a relatively small field, one that is fragmented in its diverse connections with various social science disciplines, and our work is diluted by our lack of identification with a specific comparative orientation. I do not wish to suggest that our comparative work be as narrowly defined as in some fields. For example, the single intention of comparative mysticism is to study the mystical experience, in order to determine "whether all such experiences are reducible to one pattern" (Zaehner 1957: 31). However, becoming a bit more focused in our comparative research agenda might help us make more progress in terms of our scientific contributions.

Even though our field is weakened by its methodological diversity, I believe we face a more serious challenge. In the past we have relied on developmental paradigms taken from the life and social sciences. Models such as modernization, world systems theory, and globalization, all have a deterministic edge to them. Karl Popper (1962) has labeled such orientations as historicism, because they rely on the predictive style and methodology of the natural sciences. All too often we have been guilty of historicist tendencies in comparative education and our work has suffered as a consequence. Recent trends in our field are significant, because they have been shifting our attention away from this positivist orientation toward broader considerations of knowledge production. The anti-positivistic trends in our field are refreshing but at the same time they are challenging. 
Apologists for the more conventional science-oriented comparative approaches claim this new orientation, which we are identify here as postmodernism, ought to be rejected, because it places the very foundations of comparative studies in jeopardy, ostensibly obliterating any notion of comparable categories. Defenders of science claim science allows us to establish fixed referents and general thought systems that are necessary for comparative studies to exist. Postmodernsists agree that science-oriented scholars rely on global frames of reference, but they criticize positivist assumptions, because fixed referents lock civilization into totalitarian and logocentric thought systems. Jean-François Lyotard (1984) and Michel Foucault (1980) associate science with "totalitarian theories" and "terroristic universals".

Postmodern scholars describe the world as one which is decentered, constantly changing, without the chains and conventions of modern society. Its proponents believe the stories of pluralistic contemporary societies are being written by a number of narratives and reject philosophical systems of thought, which propose some universal standard, as reflected in the orientations of scholars such as Adam Smith, Freud, Hegel, Compte, and Marx. But other scholars defending such conventional paradigms claim that postmoderns are throwing the baby out with the bath. Their postmodern epistemology would reject the possibility of establishing comparable categories.

Those defending the conventional paradigm claim postmoderns are destroying the possibility of satisfying the criteria necessary for comparison. This argument is important, and we are have elsewhere cautioned against rejecting certain metanarratives, because we have worried about localized frameworks that have no general validity, that disallow comparison, and deny the integration of cultures and harmonizing values (Rust: 1991). Legitimate metanarratives give access to knowledge of individuals, systems, and societies, providing forms of analysis that express and articulate differences, that encourage critical thinking without closing off thought and avenues for constructive action. My stance may be seen as faint hearted, because we wish to remain supportive of science while challenging the narrowness of past scientific work. We are must confess and we have great regard for science and its potential, and we agree with John Horgan (1996: 5), 
that scientists generally want to learn about reality, and I laud them for their interest in knowing more, in discovering truth. However, their tendency to disregard non-scientific ways of knowing is self-defeating. Is there a way to support science while recognizing the value of other ways of knowing?

One course of action we comparative educators might take is to reconsider our strong commitment to hierarchical developmental classification. It clearly has favored Eurocentrism and unequal power relations. We find the other comparative approaches discussed in this essay to be less hegemonic than hierarchical developmental classification, and our field might stave off the threat of anti-positivists by moving toward these more even-handed approaches.

At the same time, we feel we must reject the hegemonic claims of science. We recall, for example, that Comte believed society traversed through various stages, from religion, to philosophy, then to science. His mistake, from my vantage point, was to place these ways of knowing in a hierarchical framework, which makes philosophy a second-rate means of knowing, and religion a third-rate means of knowing. My own orientation is to place them parallel with each other. There is a place for the spiritual, a place for the philosophical, and a place for the scientific, and any attempt to place one exclusively over the other is inappropriate.

\section{Conclusion}

Comparative anatomy has a hierarchical comparative classification; comparative politics has a somewhat different orientation related to ahistorical typologies, while comparative philology traces the comparative development of languages, and comparative literature traces cultural influences across cultures.

Postmodernsists agree that science-oriented scholars rely on global frames of reference, but they criticize positivist assumptions, because fixed referents lock civilization into totalitarian and logocentric thought systems. Postmodern scholars describe the world as one which is decentered, constantly changing, without the chains and conventions of modern society. Its proponents believe the stories of pluralistic contemporary societies are being written by a number of narratives and reject philosophical systems of thought, 
which propose some universal standard. But other scholars defending such conventional paradigms claim that postmoderns are throwing the baby out with the bath. Their postmodern epistemology would reject the possibility of establishing comparable categories. Those defending the conventional paradigm claim postmoderns are destroying the possibility of satisfying the criteria necessary for comparison.

At the same time, I feel we must reject the hegemonic claims of science. We recall, for example, that Comte believed society traversed through various stages, from religion, to philosophy, then to science. His mistake, from my vantage point, was to place these ways of knowing in a hierarchical framework, which makes philosophy a second-rate means of knowing, and religion a third-rate means of knowing. My own orientation is to place them parallel with each other. There is a place for the spiritual, a place for the philosophical, and a place for the scientific, and any attempt to place one exclusively over the other is inappropriate.

\section{Bibliography}

Comte, A. 1988. Introduction to Positive Philosophy (Reprint). New York: Hacket.

Dalin, P. and V. Rust. 1998. Toward Schooling for the Twenty-first Century. London: Cassell.

Delbrück, B. 1882. Introduction to the Study of Language. Translated from the German. Leipzig: Breitkopf and Härtel.

Durkheim, E. 1893. The Division of Labor in Society. New York: Free Press.

Fraser, Stewart E. and William W. Brickman (eds.). 1968. A History of International and Comparative Education. Boston: Scott, Foresman and Co.

Highet, G. 1992. The Classical Tradition: Greek and Roman Influences on Western Literature. New York: Oxford University Press.

Holmes, B. 1981. Problems in Education: A Comparative Approach. London: Routledge and Kegan Paul.

Horgan, J. 1996. The End of Science. New York: Broadway Books.

Jary, D. and J. Jary. 1991. Collins Dictionary of Sociology. Glasgow: HarperCollins. 
Jordan, Louis Henry. 1905. Comparative Religion. Edinburgh: T. and T. Clark.

Paulston, R. G. 1993. Comparative Education as an Intellectual Field. Comparative Education, 23, no. 2, 101-14.

Paulston, R. G. 1999. Mapping the Postmodernity Debate in Comparative Education. Comparative Education Review, 42.

Rajab, T. (2015). An Applied Model of Teaching Materials to Improve Students' Speaking Skill. Jurnal Ilmiah Peuradeun, 3(1), 103-118.

Rust, V. 1991. Postmodernism and Its Comparative Education Implications. Comparative Education Review, 35 (November): 610-26.

Rust, V. 1993. The Transformation of History Instruction in East German Schools. Compare 23, nr. 3: 205-17.

Rust, V. 1997. The German Image of American Education through the Weimar Period. Paedagogica Historica: International Journal of the History of Education 33, no. 1: 25-44.

Rust, V. and Others. 1999. Research Strategies in Comparative Education. Comparative Education Review 43:

Safrina, S., \& Saminan, S. (2015). The Effect of Model Problem Based Learning (PBL). Jurnal Ilmiah Peuradeun, 3(2), 311-322.

Schneider, F. 1961. Vergleichende Erziehungswissenschaft. Heidelberg: Quelle und Meyer.

Stromquist, N. P. 1991. Educating women: The political economy of patriarchal states. International Studies in the Sociology of Education, $1,111-128$

Thomas, R. Murray. 1998. Conducting Educational Research: A Comparative View. Westport, CT: Bergin and Garvey.

Wallerstein, Immanuel. 1991. The National and the Universal: Can There Be Such a Thing as a World Culture? Pp. 91-106 in Anthony D. King (ed.), Culture, Globalization and the World System. Binghamton: SUNY at Binghamton.

Yusoff, M. Z. M., \& Hamzah, A. (2015). Direction of Moral Education Teacher To Enrich Character Education. Jurnal Ilmiah Peuradeun, 3(1), 119-132.

Zaehner, R. C. 1957. Mysticism: Sacred and profane. Oxford: Clarendon Press. 
